\title{
Upaya Peningkatan Nilai Ekonomi Sampah Plastik Dengan Program Bank Sampah Di Simo Jawar Baru Kecamatan Sukomanunggal Surabaya
}

\author{
Eky Novianarenti ${ }^{1}$, Erlinda Ningsih $^{2}$ \\ ${ }^{1}$ Teknik Mesin, Institut Teknologi Adhi Tama Surabaya \\ ekynr@itats.ac.id \\ ${ }^{2}$ Teknik Kimia, Institut Teknologi Adhi Tama Surabaya \\ erlindaningsih84@gmail.com
}

\begin{abstract}
The city of Surabaya is one of the cities known as the city of floods when the rainy season arrives and has a dirty river filled with garbage. In the past few years, the Surabaya city government began to improve and organize and create programs aimed at independence from waste. One of the efforts made by the Surabaya City Government to deal with floods and garbage accumulation is to create a waste bank program in several regions. The purpose of this service is (1) to describe the benefits and increase the economic value of waste. (2) to direct citizens to become garbage bank customers. This activity was carried out through three stages, namely crafting to the Rumah Bangkit children, training the waste bank management to the garbage bank officers with participants namely Karang Taruna and socialization and inauguration on August 19, 2018 which was attended by residents of RW 10, totalling around 300 people and inaugurated by Mayor of Surabaya. This activity begins with a briefing on waste care, the environment, and invites citizens to participate in the waste bank. Furthermore, a demo / simulation of a waste bank customer that begins with depositing plastic waste, sorting garbage, weighing garbage and finally recording / recap in a passbook. The implementation of this activity went smoothly and enthusiastically, the very high number of people and the highlight of this service was the launching of a garbage collection tool
\end{abstract}

Keywords: Surabaya waste bank, Deposit plastic, Customer simulation, Recording in a passbook, Crusher machine

\begin{abstract}
ABSTRAK
Kota Surabaya merupakan salah satu kota yang terkenal dengan sebutan kota banjir ketika musim hujan tiba dan memiliki sungai yang kotor dipenuhi sampah. Beberapa tahun ini, pemerintah kota Surabaya mulai membenahi dan menata serta membuat program - program yang bertujuan untuk merdeka dari sampah. Salah satu usaha yang dilakukan Pemerintah kota Surabaya untuk mengatasi banjir dan penumpukan sampah yaitu menciptakan program bank sampah di beberapa wilayah. Tujuan dari pengabdian ini adalah (1) untuk mendeskripsikan manfaat dan peningkatan nilai ekonomi sampah. (2) untuk mengarahkan warga menjadi nasabah bank sampah. Kegiatan ini melalui 3 tahapan yaitu crafting kepada anak-anak Rumah Bangkit, training manajemen bank sampah kepada petugas bank sampah dengan pesertanya yaitu karang taruna dan sosialisasi dan peresmian pada tanggal 19 Agustus 2018 yang diikuti oleh warga RW 10 yang berjumlah sekitar 300 orang dan diresmikan oleh Walikota Surabaya. Kegiatan ini diawali dengan pengarahan tentang kepedulian sampah, lingkungan, dan mengajak warga berpartisipasi dalam bank sampah. Selanjutnya demo/simulasi nasabah bank sampah yang dimulai dengan penyetoran sampah plastik, pilah sampah, penimbangan sampah dan terakhir pencatatan/rekap di buku tabungan. Pelaksanaan kegiatan ini berjalan lancar dan antusias warga yang sangat tinggi dan puncak acara pengabdian ini adalah launching alat pencacah sampah.
\end{abstract}

Kata kunci: Bank sampah Surabaya, Penyetoran sampah plastik, Simulasi nasabah, Pencatatan buku tabungan, Mesin pencacah

\section{PENDAHULUAN}

Surabaya merupakan kota metropolitan terbesar kedua setelah Jakarta, kota yang menjadi tujuan kedua bagi para investor lokal dan asing untuk berinvestasi. Kota Surabaya merupakan kota yang terkenal dengan kota banjir ketika musim penghujan dan dilansir Badan Pusat Statistik 
Nasional terdapat sekitar 84.51 persen sampah yang tidak dipilah (BPS, 2017). Hal ini disebabkan oleh kesadaran warga Surabaya yang rendah. Banyak saluran air yaitu sungai atau got dijadikan tempat pembuangan sampah oleh warga sekitar. Di samping itu jumlah saluran air yang kurang ketika hujan deras tiba sehingga air tidak menemukan saluran air. Hal ini sangat berpengaruh terhadap siklus perekonomian di Surabaya jika hal tersebut tidak segera ditanggulangi (Krisnani, 2017).

Beberapa tahun ini, Pemerintahan Kota Surabaya mulai berbenah, menata, dan membuat program-program yang berkaitan dengan lingkungan yang sehat dan bersih sehingga dapat mengurangi frekuensi banjir. Program - program yang dilakukan diantaranya menata taman, memperbanyak area hijau, bank sampah, menghimbau warga tingkat RT/RW merdeka dari sampah, dan yang terbaru adalah naik bus kota gratis cukup hanya menukarkan tiket dengan sampah plastik.

Peraturan tentang pengelolaan sampah rumah tangga sudah tertuang dalam peraturan pemerintah Republik Indonesia Nomor 81 Tahun 2012, dalam kebijkan tersebut tidak hanya menjadi tanggung jawab pemerintahan sekitar tapi masyarakat juga ikut berperan dalam proses pengambil keputusan, penyelenggaraan, dan pengawasan dalam pengolahan sampah rumah tangga (Inayah dan Suprapto, 2017).

Bank sampah merupakan salah satu cara untuk pengelolaan sampah agar memiliki nilai ekonomi. Salah satu pemukiman di Surabaya Barat yaitu Simo Jawar Baru adalah kawasan yang cukup padat dan mayoritas warganya berprofesi sebagai pengepul sampah. Sehingga solusi untuk mensinergikan program pemerintah kota Surabaya dan meningkatkan perekonomian di daerah Simo Jawar Baru maka perlu dibentuk program bank sampah.

\section{METODE PELAKSANAAN}

Berdasarkan data survey sebelum dilakukan sosialisasi di daerah Simo Jawar Baru, bahwa masalah kebersihan lingkungan atau sampah yang masih belum terformalkan menimbulkan kurangnya kepekaan pada warga yang berprofesi sebagai pengepul sampah. Hal ini sangat rentan terhadap sebuah penyakit, banjir, dan jauh dari Perilaku Hidup Bersih dan Sehat (Kurniawan, 2017). Selain fasilitas pengetahuan merupakan faktor yang penting bagi mereka dalam pengelolaan sampah. Fasilitas PHBS juga masih tergolong minim atau bahkan tidak memadai. Prioritas permasalahan mitra dapat terindentifikasi sebagai berikut:

1. Pengetahuan tentang pengelolahan sampah masih belum terformalkan

2. Sarana pengelolahan sampah belum diberikan prioritas yang cukup

3. Sebagian besar lapisan masyarakat belum tersentuh paradigma dan pola berpikirnya tentang manfaat pengelolaan sampah serta peningkatan nilai ekonomi sampah.

\section{Solusi yang ditawarkan}

Solusi dari permasalahan mitra tersebut adalah dilakukan pengarahan (sosialisasi) pengolahan sampah dan peningkatan nilai ekonomi sampah yaitu dengan memberikan fasilitas wadah bank sampah dengan melibatkan pemuda sekitar yang tergabung dalam Karang Taruna tingkat RT/RW sebagai petugas untuk melayani nasabah bank sampah serta ikut mengajak warga sekitar untuk berpartisipasi. Sehingga solusi ini dapat bersinergi dengan visi misi pemerintahan Kota Surabaya dan meningkatkan perekonomian warga serta menciptakan lingkungan bersih dan sehat.

Metode yang dilakukan adalah sosialisasi yang semua level ikut berpartisipasi baik dari tingkat anak-anak, remaja (karang taruna), sampai ibu-ibu yang meriah dengan bersamaan penyerahan hadiah lomba Agustusan dan mengadakan lomba rumah bersih untuk RW 10 yang terdiri dari 5 RT untuk meningkatkan partisipasi warga dalam bank sampah sebagai nasabah.

Adapun rencana strategi kegiatan yang akan dilakukan untuk meningkatkan partisipasi masyarakat dalam bank sampah ini adalah: 
1. Mengadakan koordinasi untuk meminta dukungan langsung Pemerintahan Kota Surabaya yaitu Walikota

2. Himbauan dan arahan untuk warga Simo Jawar dari DKRTH, Kecamatan, Kelurahan, RW 10 dan RT dalam partisipasi dan antusias mengikuti kegiatan ini.

3. Karang taruna tingkat RT dalam RW 10 sebagai penggerak terlibat dalam pengelolahan dan manajemen bank sampah.

\section{HASIL DAN PEMBAHASAN}

Kegiatan pengabdian ini yang bertujuan untuk mensosialisasikan bank sampah dan peduli lingkungan berlansung kurang lebih 5-7 bulan yang terdiri dari tahap pelatihan crafting, tahap training manajemen bank sampah dan tahap sosialisasi bank sampah.

\section{a. Kegiatan pelatihan crafting (Pemanfaatan Plastik Bekas)}

Tahap ini dilakukan dengan agenda memberikan pelatihan crafting untuk anak-anak Rumah Bangkit RT 3 di Simo Jawar sekaligus merupakan langkah awal untuk memberikan pembelajaran sejak dini tentang kepedulian sampah kepada anak-anak terhadap lingkungan sekitar dengan bahasa penyampaian yang mudah diterima oleh anak anak yaitu dongeng. Di samping itu, anak-anak dilatih untuk memanfaatkan sampah plastik menjadi barang yang lebih berguna yaitu dihias dan dilukis serta dibentuk kreasi sesuai dengan kreatifitas masing-masing (Eky, 2018).
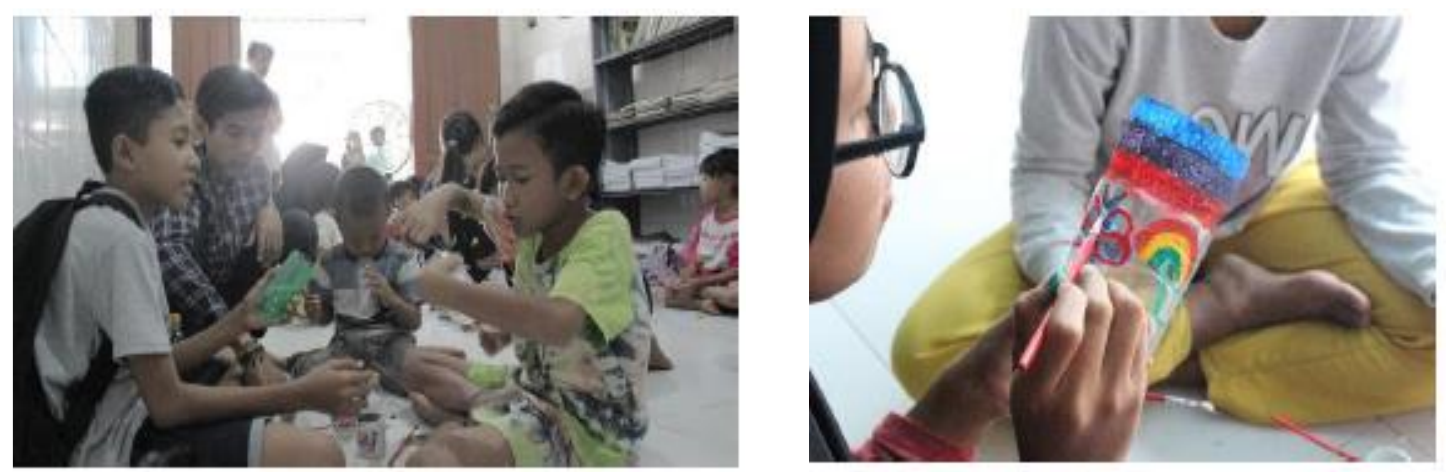

Gambar 1. Proses water coloring pada botol plastik dilakukan secara berkelompok

\section{b. Training Manajemen Bank Sampah}

Tahap ini merupakan tahapan yang sangat penting. Tahapan ini bertujuan untuk memberikan training manajemen pengelolaan bank sampah kepada karang Taruna tingkat RW yang merupakan bakal calon petugas bank sampah. Materi yang disampaikan mengenai mekanisme mendaftar menjadi nasabah bank sampah, sistem pencatatan daftar harga tiap jenis sampah, penjadwalan pengumpulan sampah oleh nasabah, serta penarikan uang oleh nasabah. Mekanisme dimulai dari pendaftaran, pemilahan sampah, penimbangan, penerimaan buku tabungan, dan terakhir rekap. Sedangkan training manajemen berlangsung dengan baik yang mengusung jargon "Pilah sampah jadikan rupiah". 

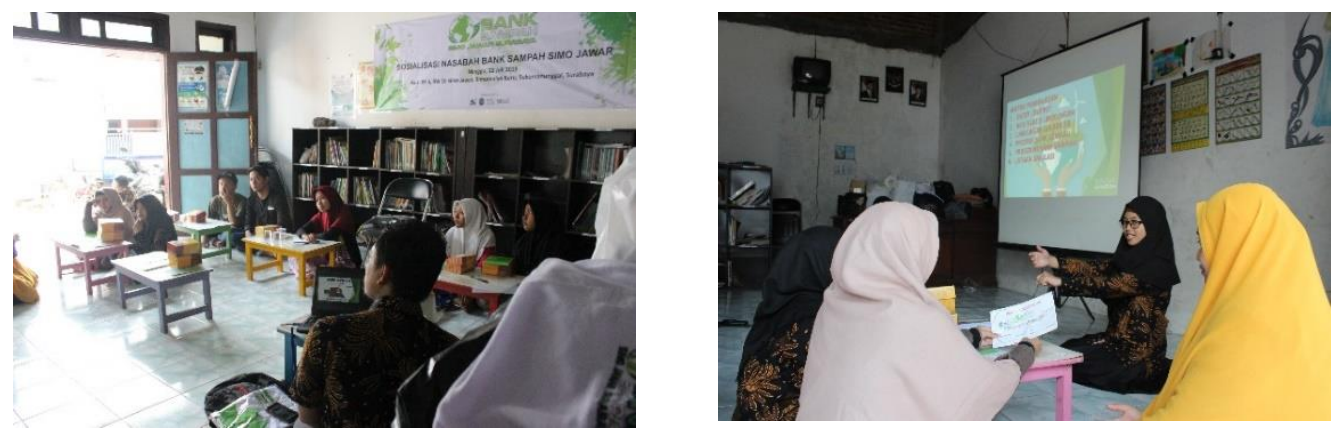

Gambar 2. Antusias Karang Taruna dan penyampaian materi

\section{c. Sosialisasi dan peresmian Bank sampah}

Kegiatan ini dilakukan dengan ceramah (ajakan) dan tanya jawab yang dilakukan pada tanggal 19 Agustus 2018 dengan mengikut sertakan anak-anak dan semua warga RW 10 dan dimeriahkan dengan pembagian hadiah 17 Agustusan. Pengarahan, himbauan, dan ajakan kepada masyarakat agar peduli lingkungan, manfaat bank sampah, ajakan untuk menjadi nasabah disampaikan oleh Walikota Surabaya dan praktisi Bank Sampah. Pada kegiatan ini warga yang berminat menjadi nasabah membawa sampah dan dilakukan simulasi mulai dari pendaftaran, pemilahan, penimbangan, pencatatan dalam buku tabungan dan rekap. Puncak dari acara ini adalah penyerahan sarana pendukung bank sampah yaitu mesin pencacah sampah plastik. Rangkaian pelaksanaan sosialisasi ini berlangsung dengan ramai terkendali. Antusias warga untuk menjadi nasabah melebihi dari target yang diperkirakan.

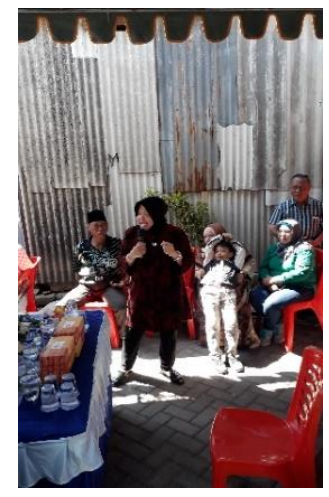

(a)

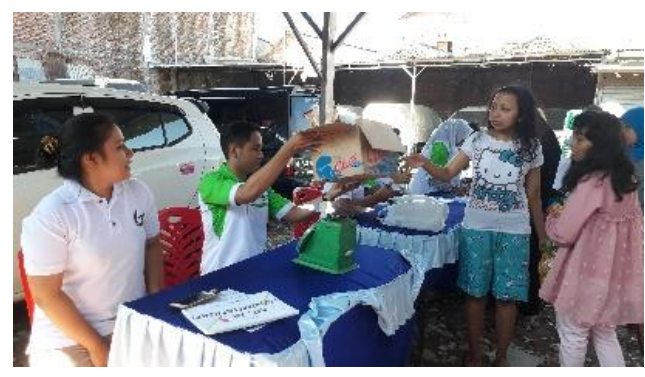

(c)

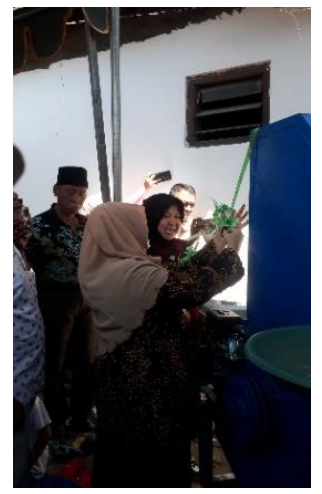

(b)

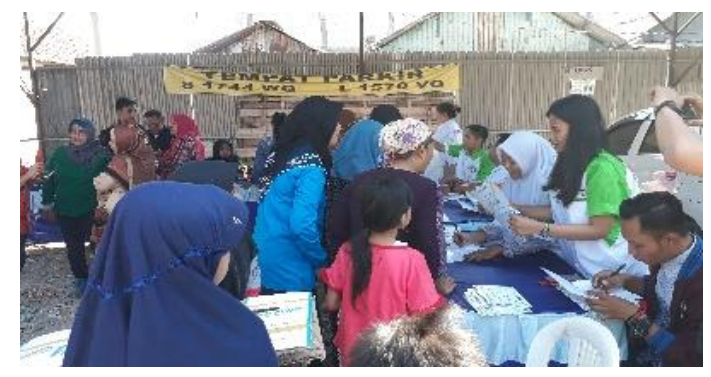

(d)

Gambar 3. Sosialisasi meliputi (a) Ajakan dari Walikota (b) Pengguntingan pita (c) Penimbangan dan (d) rekap data nasabah bank sampah 
Data perekonomian terkini dari wilayah Simojawar semenjak diberlakukannya Bank Sampah per tanggal 19 Agustus 2018 secara akurat dan berimbang disajikan dalam bagan seperti berikut

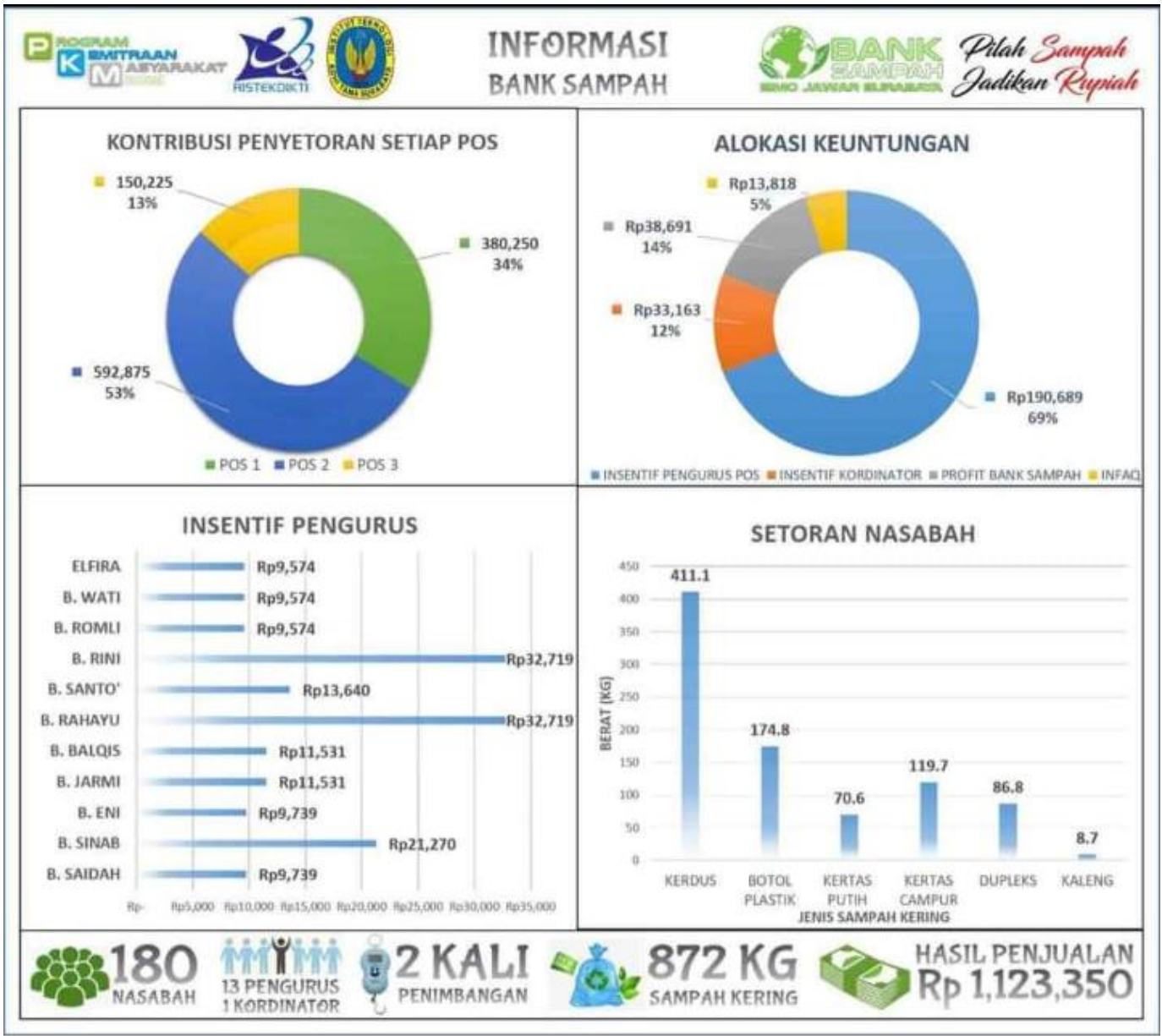

Gambar 4. Rekapitulasi data bulanan bank sampah setelah 2 bulan berjalan

\section{KESIMPULAN}

Kesimpulan yang dapat dipaparkan dari hasil pengabdian ini adalah sebagai berikut:

a. Terjadi penambahan pengetahuan anak-anak Rumah Bangkit terhadap kepedulian sampah dan menjadikan sampah bahan untuk berkreasi (crafting).

b. Terbentuknya manajemen bank sampah dan petugasnya untuk mengelola bank sampah di Simo Jawar Baru RW 10.

c. Peningkatan nasabah bank sampah untuk hari pertama pendaftaran yang waktu bersamaan dengan pengenalan bank sampah tersebut.

\section{UCAPAN TERIMA KASIH}

Ucapan terima kasih kepada DRPM Dikti, Kementrian Riset dan Teknologi Tinggi yang membantu terlaksananya pengabdian masyarakat terutama terkait pendanaan pengabdian melalui skim Program Kemitraan Masyarakat (PKM) tahun 2018 


\section{DAFTAR PUSTAKA}

Eky Novianarenti, Erlinda Ningsih, (2018). P Pembinaan Untuk Menumbuhkan Kepedulian Dan Cinta Lingkungan Pada Kelompok Belajar Rumah Bangkit Di Wilayah Simo Jawar Baru Kecamatan Sukomanunggal Surabaya JURNAL Semnas Universitas 17 Agustus Surabaya Pengabdian Pada Masyarakat. Volume 1, No. 1, Agustus 2018: Page 228-234. P-ISBN: 978-602-50699-8-7 bisa di akses di http://jurnal.untagsby.ac.id/index.php/semnasuntag/article/view/1696/1441

Kurniawan,H 2017. Upaya peningkatan derajat kesehatan pada anak di panti asuhan melalui edukasi perilaku hidup bersih dan sehat. Jurnal Pengabdian Masyarakat IPTEKS. Vol.3 No.1 Juni 2017.e-ISSN:2528-116X p-ISSN:2527-5216.

Krisnani, H., Humaedi, S., Fedryansyah, M., Asiah, D. H. S., Basar,G. K., Sulastri, S., Mulyana, N. (2017). Perubahan Pola Pikir Masyarakat Mengenai Sampah Melalui Pengolahan Sampah Organik Dan Non Organik Di Desa Genteng, Kecamatan Sukasari, Kab. Sumedang. Jurnal Penelitian \& PPM. Vol 4, No: 2 Hal: 129 - 389 Juli 2017. ISSN: 2442-448X.

Inayah,N dan Suprapto, R., 2017. Pendidikan karakter melalui pembentukan bank sampah berbasis pesantren di PP Ibnu Sina Genteng Banyuwangi. Jurnal pengabdian kepada masyarakat. ISSN : 2579-8375 (print); ISSN : 2579-8391

Persentase Rumah Tangga Menurut Provinsi dan Perlakuan Memilah Sampah Mudah Membusuk dan Tidak Mudah Membusuk (https:///www.bps.go.id/linkTabelStatis/view/id/1360) 